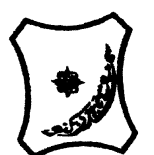

Bayero Journal of Pure and Applied Sciences, 12(2): 176 - 181

Received: June, 2019

Accepted: December, 2019

ISSN $2006-6996$

\title{
BODY COMPOSITION IN CHILDREN WITH CEREBRAL PALSY AND ITS RELATIONSHIP WITH DYNAMIC MUSCLE STRENGTH, BALANCE AND ENERGY COST OF AMBULATION
}

Badaru, U.M. ${ }^{1}$, Dabo, L.S. ${ }^{1}$, Nuhu J.M. ${ }^{1}$, Ahmad, R.Y. ${ }^{1}$, Abba M.A. ${ }^{1}$ and Shittu, A. ${ }^{1}$

${ }^{1}$ Department of Physiotherapy, Faculty of Allied Health Sciences, Bayero University, Kano, Nigeria

Correspondence author: umbadaru.pth@buk.edu.ng OR badaruum@yahoo.com

Mobile: +2348035913759

ABSTRACT

Cerebral palsy (CP) causes walking disability in children which could lead to profound changes in body composition. This study assessed relationship between body composition and each of dynamic muscle strength, mobility and energy cost of ambulation (ECA) among children with CP. The cross sectional survey, recruited participants from a secondary and a tertiary hospitals in Kano. Body composition was assessed with BMI for age charts and skin fold calipher. Dynamic muscle strength, balance and ECA were assessed with step-up test, time-up-and-go test and physiological cost index respectively. Data was analysed with Pearson Product Moment Correlation and unpaired $t$ test at alpha level of $P<0.05$ using SPSS version 20 and Microsof excel. Twenty four children took part in the study, 13 (54.2\%) females and 11(45.8\%) males. Their mean age was $10.0 \pm 4.6$ years. Majority of them 17 (70.8\%) were underweight. The mean percent body fat score was $11.78 \pm 3.85$, with females having significantly higher amount of body fat than males $(t=-3.37 ; P=0.003)$. There were no significant correlations between body compositon and each of dynamic muscle strength, balance and ECA $(p>0.05)$. It was concluded that about two-thirds of the children with $C P$ in the study are underweight and having low percent body fat. Body composition may not have significant influence on the muscle strength, stability and the energy expended during walking function. Paediatricians and physiotherapists should encourage caregivers of children with CP to feed them with balanced diet in order to avoid diseases associated with malnutrition.

Keywords: cerebral palsy, body composition, muscle strength, balance and physiological cost index.

\section{INTRODUCTION}

The physical disability caused by Cerebral Palsy (CP) often leads to profound changes in body composition (Park et al., 2011; Finbraten et al., 2015). Although children with CP are often viewed as being undernourished with stunted growth, a number of studies propose however that children with $\mathrm{CP}$ are at a high risk of becoming overweight probably because of their low level of physically activity and sedentary life (Rogozinski et al., 2007; Reinehr et al., 2010; Park et al., 2011). Studies by Rogozinski et al. (2007) and Reinehr et al. (2010) have reported on the rapid increase in the prevalence of overweight and obesity among children with $\mathrm{CP}$. Other studies also reported that ambulant children with $\mathrm{CP}$ tend toward having increased prevalence of being overweight (Hurvitz et al., 2008; Park et al., 2011). There is however dearths of published studies documenting the prevalence of overweight or obesity among ambulatory children with $\mathrm{CP}$ in Nigeria.

It has been suggested that body composition could have influence on the level of physical functioning and activity of individuals (Nene et al., 1993; Marques et al., 2011). Although muscle strength has been found to have influence on the walking ability and gait in children with CP (Eek 2009), Flanagan et al. (2011) has opined that body composition is another factor that could exert similar influence on activity and physical functioning in children with CP which should not be overlooked. It is however not clear in the literature whether body composition or in particular excess body fat could have any influence on the dynamic strength, balance and Energy Cost of Ambulation (ECA) in children with CP. This study therefore, assessed the relationship between body composition and each of muscle strength, balance and ECA in children with CP. 
BAJOPAS Volume 12 Number 2, December, 2019 MATERIALS AND METHODS

The study was a cross-sectional survey in which children with $\mathrm{CP}$ who are attending treatment at the out-patient unit of Physiotherapy Departments in Aminu Kano Teaching Hospital (AKTH) Kano and Murtala Muhammad Specialist Hospital (MMSH) Kano were recruited using purposive sampling technique. Inclusion criteria include: children with $\mathrm{CP}$ who are able to ambulate with or without walking aid (GMFCS 1111) and the ablity to adhere to simple instructions. Stadiometer (SECA/Germany) was used to measure height and weight, skinfold caliper (Country technologies) was used to measure the skin fold thickness, body mass index-for-age percentiles charts (from American Center for Disease Control) was used to categorize the Body Mass Index (BMI) based on percentiles.

\section{Data Collection Procedure}

Ethical approval was sought from the ethics committees of Aminu Kano Teaching Hospital (NHREC/MAC/21/08/2008/AKTH/EC/1339) and Kano State Hospitals Management Board for Murtala Muhammad Specialist Hospital before the commencement of data collection. Informed consent was obtained from the participants and their caregivers.

\section{Assessment of obesity}

BMI for age percentile was used to determine obesity. The BMI was first determined by dividing weight of the children by the quare of their height $\left(\mathrm{W} / \mathrm{H}^{2}\right)$. On the BMI-for-age chart, age was on the horizontal axis and BMI was on the vertical axis. The appropriate percentile score for each child was obtained at the intersection of age and BMI.

Categorization of BMI for age percentiles BMI for age $<5^{\text {th }}$ percentile was considered as underweight, $\geq 5^{\text {th }}$ to $<85^{\text {th }}$ percentile was considered normal weight, $\geq 85$ th percentile to $<95$ th percentile was considered risk of overweight, and $\geq 95^{\text {th }}$ percentile was considered overweigh/obese (Liusuwan et al., 2007).

\section{Assessment of percent body fat}

This was assessed with skinfold caliper as a measure of subcutaneous fat to the nearest $0.1 \mathrm{~mm}$. The following Slaughter equations were used to measure the percent body fat

a. $1.21 \times$ (triceps + subscapular) $-0.008 \mathrm{x}$ (triceps + subscapular) $^{2}-3.2$ for black males

b. $\quad 1.33 \times$ (triceps + subscapular) $-0.013 \times$ (triceps + subscapular) $^{2}-2.5$ for all females (Dezenberg et al., 1999).
Measurement of dynamic muscle strength

This was measured with the step-up test. It involved counting the total number of times a child performed step-up and down task on the first step of a staircase in 30 seconds (Blundell et al., 2003). Children that perform greater number of step-up and down task per unit time were regarded as having better dynamic strength.

\section{Assessment of balance}

This was assessed using the Time-Up-and-Go (TUG) test. Each child was asked to sit back comfortably on a standard arm chair. They were asked to stand up from the chair and walk round a cone and come back to sit on the chair again. The chair was placed three metres away from the cone. Children that completed the TUG test in less total time were rated as having better balance.

\section{Assessment of energy cost of ambulation} (ECA)

The physiological cost index (PCI) was used in the assessment of ECA. Each child was asked to walk 20 meters distance. The heart-rate was measured before and immediately after the 20 meters-walk using standard procedure. The PCI (beats per meter) was calculated as the diference between walking and resting heart rates (beats/min) divide by walking speed (meters/min) (Bailey and Ratcliffe, 1995; Delussu et al., 2014).

\section{Data Analysis Procedure}

Data was summarized using descriptive statistics of frequency, mean and standard deviation. Relationship between body composition and each of balance, dynamic muscle strength and ECA was assessed with Pearson's correlation. Unpaired $t$ test was used to assess mean differences in percent body fat, balance, and dynamic muscle strength and ECA between males and females. Statistical analysis was performed using SPSS version 20.0. at $P<0.05$ alpha level and Microsoft excel.

\section{RESULTS}

\section{Characteristics of participants}

Twenty four children with CP participated in this study, $11(45.8 \%)$ are males and $13(54.2 \%)$ are females. The mean age of the children was $10 \pm$ 4.61years, age range 4-18years and majority of them $20(83.3 \%)$ could walk without any walking aid. These results are presented in Table 1.

The mean height of the children was $1.27 \pm$ $0.25 \mathrm{~m}$, range $0.90 \mathrm{~m}-1.80 \mathrm{~m}$. The meanweight was $23.67 \pm 10.8 \mathrm{~kg}$, range $11.00 \mathrm{~kg}-55.00 \mathrm{~kg}$. The mean balance score was $18.80 \mathrm{sec} \pm$ $10.41 \mathrm{sec}$, range $10.00 \mathrm{sec}-55.00 \mathrm{sec}$ as presented in Table 2. 
BAJOPAS Volume 12 Number 2, December, 2019

Majority of the children 17(70.83) were underweight and $5(20.83 \%)$ had normal weight, $2(8.33 \%)$ were at risk of overweight while none of them was obese. Further analysis revealed that most of the males 10 (58.82\%) were underweight when compared with their female conterparts $7(41.18 \%)$. None of the males was also found to be at risk of overweight $0 \%$ as presented in figure 1

This study found significant gender difference in percent body fat (male $=9.48 \pm 2.14$; female $13.89 \pm 3.86, \mathrm{t}=-3.371, \mathrm{P}=0.003)$, but there was no significant gender difference in balance (male=16.64 \pm 5.24; female $=20.62 \pm 13.31$, $\mathrm{t}=-0.930, \mathrm{P}=0.362$ ), ECA (male $=0.14 \pm 0.25$; female $=0.98 \pm 2.32, \mathrm{t}=-1.194, \mathrm{P}=0.245)$ and dynamic muscle strength (male $=10.18 \pm 4.21$; female $=9.23 \pm 5.45, t=0.471, P=0.642$ ).

Furthermore, there were insignificant correlations between body compositon and each of dynamic muscle strength $(r=-0.015, p=$ $0.945)$, balance $(r=0.107, p=0.620)$ and ECA $(r=0.256, p=0.228)$.

Table 1: Characteristics of participants

\begin{tabular}{|c|c|c|}
\hline Variables & $\mathbf{N}$ & $\%$ \\
\hline \multicolumn{3}{|l|}{ Sex } \\
\hline Male & 11 & 45.8 \\
\hline Female & 13 & 54.2 \\
\hline \multicolumn{3}{|l|}{ Child age category } \\
\hline $4-10$ years & 13 & 54.2 \\
\hline >10years & 11 & 45.8 \\
\hline \multicolumn{3}{|l|}{ Mother income } \\
\hline Below minimum wage & 19 & 79.2 \\
\hline Low income & 3 & 12.5 \\
\hline Average income & 1 & 4.2 \\
\hline High income & 1 & 4.2 \\
\hline \multicolumn{3}{|l|}{ Walking aid } \\
\hline Cane & 1 & 4.2 \\
\hline Walking frame & 3 & 12.5 \\
\hline None & 20 & 83.3 \\
\hline \multicolumn{3}{|c|}{ Age category of mother } \\
\hline $20-30$ years & 8 & 33.3 \\
\hline $30-40$ years & 10 & 41.7 \\
\hline >40years & 6 & 25.0 \\
\hline \multicolumn{3}{|c|}{ Level of education of mother } \\
\hline None & 4 & 16.7 \\
\hline Primary & 6 & 25.0 \\
\hline Secondary & 7 & 29.2 \\
\hline Tertiary & 7 & 29.2 \\
\hline \multicolumn{3}{|l|}{ Child schooling } \\
\hline Yes & 18 & 75.0 \\
\hline \multicolumn{3}{|l|}{$\begin{array}{l}\text { No } \\
\text { Type of CP }\end{array}$} \\
\hline Spastic & 15 & 62.5 \\
\hline Athetoid & 4 & 16.7 \\
\hline Ataxic & 5 & 20.8 \\
\hline Mixed & 0 & 0 \\
\hline
\end{tabular}

Keys: $\mathbf{N}=$ frequency, $\%=$ percent, $\mathbf{p}=$ percentile 
BAJOPAS Volume 12 Number 2, December, 2019

Table 2: Dynamic strength, balance and body composition variables

\begin{tabular}{lcc}
\hline Variables & Mean \pm SD & Ranges \\
\hline Height $(\mathrm{m})$ & $1.27 \pm 0.25$ & $0.90-1.80$ \\
Weigth $(\mathrm{kg})$ & $23.67 \pm 10.80$ & $11.00-55.00$ \\
Balance score $(\mathrm{sec})$ & $18.79 \pm 10.41$ & $10.00-55.00$ \\
Dynamic strength & $9.67 \pm 4.84$ & $2.00-21.00$ \\
Energy cost of ambulation & $0.59 \pm 1.74$ & $-2.10-7.50$ \\
RHR (beat/min) & $87.88 \pm 13.87$ & $52.00-108.00$ \\
EHR (beat/min) & $94.08 \pm 15.60$ & $60.00-120.00$ \\
Percentage body fat & $11.87 \pm 3.85$ & $7.04-18.90$ \\
\hline
\end{tabular}

Keys : $\mathbf{\text { SD }}=$ Standard deviation, $\mathbf{k g}=$ kilogram $\mathbf{R H R}=$ Resting Heart Rate, EHR = Exercise Heart Rate, $\mathbf{m}=$ meters, $\mathbf{s e c}=\mathbf{s e c o n d s}$

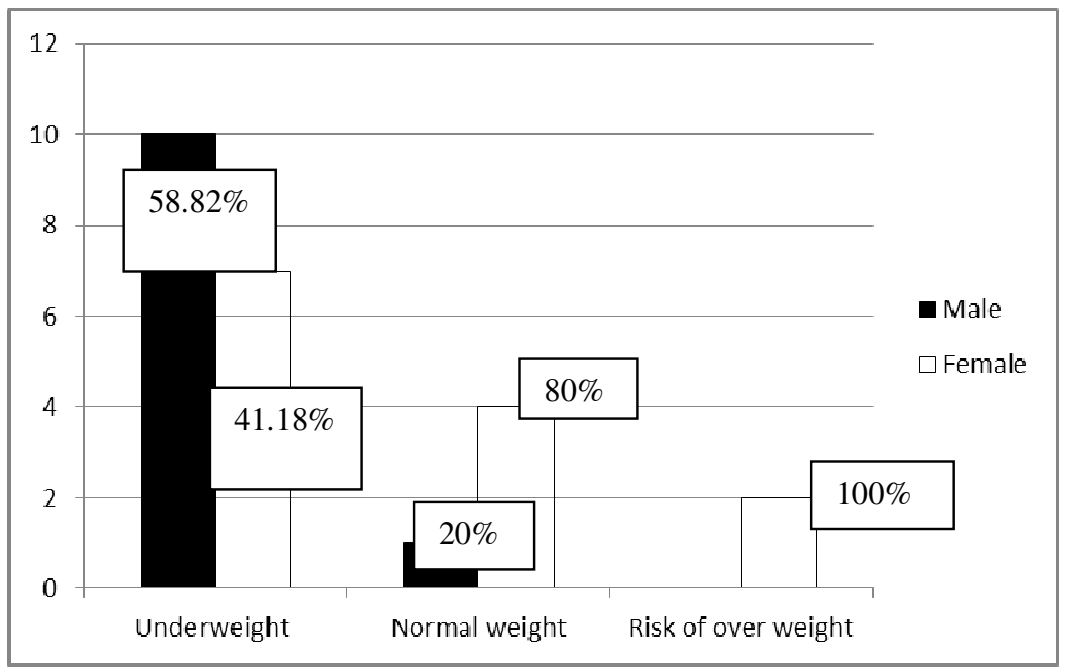

Figure1: Body weight distribution among children with CP based on gender

\section{DISCUSSION}

The result of this study showed that about twothirds of the study participants were underweight. The possible reason for the result obtained in this study could be that the children were malnourished probabbly due to the fact that majority of their caregivers earn monthly income below the minimum wage of $\$ 18,000$. As such some of them may not afford to take good care of the children considering their meagre earnings. On the contrary, a retrospective 13 years study showed that ambulatory individuals with $\mathrm{CP}$ are more prone to being overweight than underweight (Park et al., 2011). Hurvitz et al. (2008) also suggested that ambulatory children with $\mathrm{CP}$ tend toward having higher prevalence of overweight while underweight was more prevalent in nonambulatory children. In the same vein, a study by Rogozinski et al. (2007) found that children with mild CP (GMFCS level II) had twice the odds of becoming obese than did children with greater involvement (GMFCS level III).

The mean balance (TUG) score in this study was lower compared with 19.8 and 25.4 that were reported by Salem and Godwin (2009) and higher when compared with 10.1 and 8.1 that were reported by Katz-Leurer et al. (2009). This implies that the children in this study had higher balance than the children in the study by Salem and Godwin (2009) but they however have lower balance when compared with particpants in Katz-Leurer et al. (2009). This is because high TUG score means low balance and vice versa. The possible reason for the difference in the outcome of this study and that of Katz-Leurer et al. (2009), on balance could be due to the fact that this study recruited only children with $\mathrm{CP}$ but Katz-Leurer et al. (2009) recruited children with $\mathrm{CP}$ and head injury and it is possible that children with head injury may have higher balance (Low TUG score) that children with CP. The outcome of this study revealed that children with $\mathrm{CP}$ have high dynamic muscle strength. This is because, children in this study were able to perform average of 9.67 repetitions in 30 seconds that is, about 19 repetitions per minute. This was higher than the average of about 13 repetitions per minute that was reported by Katz-Leurer et al. (2009) and Blundell et al. (2003). 
BAJOPAS Volume 12 Number 2, December, 2019

The children with CP in Blundell et al (2003) performed an average of 3.3 repetitions in 15 seconds and this gave average of 13.2 repetitions per minute.

The average ECA in this study was within normal limits for childen with $C P$ based on the research report that, the ECA of apparenthy healthy children was 0.1 (beats per meters) and that of the children with CP was 6 times higher (Raja et al., 2007). Very high levels of ECA of 5.8 and 5.1 have also been reported by Katz-Leurer et al (2009). The implication of this finding is that the children in this study did not expend so much energy when walking, with appreciable gait efficiency and negligible locomotor disability (Bailey and Ratcliffe, 1995).

The average percent body fat in this study (i.e.11.87) was lower than the 21.5, 20.7, and 22.9 percent body fat that were reported by Finbraten et al. (2015). This implies that the chidren with $\mathrm{CP}$ in this study have very low body fat. Futthermore, the female participants in this study have significantly greater amount of body fat than the male participants. This implies that males are more malnourished than their female counterpart. Finally, it was found in this study that there was no significant relationship between body composition in children with $\mathrm{CP}$ and each of their Dynamic Muscle Strength,

\section{REFERENCES}

Bailey, M.J., and Ratcliffe, C.M. (1995): Reliability of physiological cost index measurements in walking normal subjects using steady-state, non-steadystate and post-exercise heart rate recording. Physiotherapy, 81 (10): 618623

Blundell, S.W., Shepherd, R.B., Dean, C.M., Adams, R.D., and Cahill, B.M. (2003): Functional strength training in cerebral palsy: A pilot study of a group circuit training class for children aged 4-8 years. Clinical Rehabilitation, 1(7): 4857.

Delussu, A.S., Morone, G., Iosa, M., Bragoni, M., Paolucci, S., and Traballesi, M. (2014): $\quad$ Concurrent validity of physiological cost index in walking overground and during Robotic training in subacute stroke patients, BioMed Research International, 2014:1-6.

Dezenberg, C.V., Nagy, T.R., Gower, B.A., Johnson, R., and Goran, M.I., (1999): Predicting body composition from anthropometry in pre-adolescent children, International Journal of Obesity, 23: 253-259.
Balance and ECA. This result implies that the amount of fatness in the body of children with $\mathrm{CP}$ may not have significant influence on their functional muscle strength, stability and amount of energy they expend during walking function. The possible reason for the result obtained above may be because the percent body fat is very low and most of the children were underweight, and in this situation, body composition is not likely to have any impact on any of the variables of walking function

\section{CONCLUSION}

About two-thirds of the ambulant children in this study were underweight and majority of the underweight are males. The children generally have low percent of body fat. Amount of fatness in children with $\mathrm{CP}$ may not have significant influence on their functional muscle strength, stability and amount of energy they expend during walking function. Paediatricians and physiotherapist should encourage caregivers of children with CP to feed them with balanced diet to avoid diseases associated with malnutrition.

\section{Authors' contributions}

All the authors have equal contributions in the design of this research, data collection, data management and research report

Eek, M.N., (2009): Muscle strength, gross motor function and gait pattern in children with cerebral palsy. A doctoral thesis in the Institute of Clinical Sciences/department of Pediatrics, Sahlgrenska Academy, University of Gothenburg. Accessed at https://gupea.ub.gu.se/bitstream/2077/ 18969/1/gupea 207718969 1.pdf

Finbraten, A., Martins, C., Andersen, G.L., Skranes, J., Brannsether, B., Juliusson, P.B., Syversen, U., Stevenson, R.D., and Vik, T. (2015): Assessment of body composition in children with cerebral palsy: a cross-sectional study in Norway. Developmental Medicine and Child Neurology, 57: 858-864

Flanagan, A., Krzak, J., Hassani, S., Bagley, A., Gorton, G., Romness, M., Tylkowski, C., Abel, M., Johnson, B., and Oeffinger, D., (2011): Relationships among Strength, Body Composition, and Measures of Activity in Ambulatory Children with Cerebral Palsy: A CrossSectional Study. Critical Reviews in Physical and Rehabilitation Medicine, 23(1-4): 15-29.

Hurvitz, E.A., Green, L.B., Hornyak, J.E., Khurana, S.R., and Koch, L.G., (2008): Body mass index measures in children 
BAJOPAS Volume 12 Number 2, December, 2019 with cerebral palsy related to gross motor function classification: a clinicbased study. American Journal of Physical Medicine and Rehabilitation, 87(5): 395-403.

Katz-Leurer, M., Rotem, H., Keren, O., and Meyer, S., (2009): The effects of a 'home-based' task-oriented exercise programme on motor and balance performance in children with spastic cerebral palsy and severe traumatic brain injury. Clinical Rehabilitation. 23:714-24.

Liusuwan, R.A., Widman, M.S., Richard, M.S., Dennis, M.D., and Craig, M.D., (2007): Body composition and resting energy expenditure in patients aged 11 to 21years with spinal cord dysfunction compared to controls:comparisons and relationships among the groups. The Journal of Spinal Cord Medicine. 30: 1-7.

Marques, E., Joana, C., Andreia, P., Flávia, W., and Jorge, $M$ (2011): the influence of physical activity, body composition, and lower extremity strength on walking ability. Motor Control. 15: 494-506.

Nene, A.V., Evans, G.A., and Patrick, J.H., (1993): Simultaneous multiple operations for spastic diplegia: Outcome and functional assessment of walking in 18 patients, The Journal of Bone and
Joint Surgery, British Volume. 75(3): 488-94.

Park, E.S., Chang, W.H., Park, J.H., Yoo, J.K., Kim, S.M., and Rha, D.W. (2011): Childhood obesity in ambulatory children and adolescents with spastic cerebral palsy in Korea. Neuropediatrics. 42(2): 60-6.

Raja, K., Joseph, B., Benjamin, S., Minocha, V., Rana, B., (2007) Physiological cost index in cerebral palsy: its role in evaluating the efficiency of ambulation. Journal of Pediatric Orthopaedics. 27(2):130-6.

Reinehr, T., Dobe, M., Winkel, K., Schaefer, A., and Hoffmann, D., (2010): Obesity in Disabled Children and Adolescents: An Overlooked Group of Patients. Deutsches Arzteblatt International. 107(15): 268 - 275.

Rogozinski, B.M., Davids, J.R., Davis, R.B., Christopher, L.M., Anderson, J.P., Jameson, G.G., and Blackhurst, D.W. (2007): Prevalence of obesity in ambulatory children with cerebral palsy. The Journal of Bone and Joint Surgery, American volume. 89(11): 2421-6.

Salem, Y., and Godwin, E.M. (2009): Effects of task-oriented training on mobility function in children with cerebral palsy. Neuro Rehabilitation. 24:307-13. 